\title{
The Present Situation and Investigation of the Pension Service System in Xi 'an
}

\author{
Libing Liu*, Hong Bai, Mengdi Wu, Xujing Xie, Qingyu Fan, Jiu Cheng, Rui Meng and Jiao Meng \\ Medical school of Xi 'an Peihua university, Xi 'an, Shaanxi, China. \\ *corresponding author
}

Keywords: Aging of Population, Pension Service System, Xi'an

\begin{abstract}
Objective: To investigate the status quo of pension service system in Xi'an, analyze the existing problems and propose corresponding countermeasures. Method: The elderly and pension service institutions in $\mathrm{Xi}$ 'an were studied. Results: Survey showed that about $63 \%$ of the elderly in Xi'an are mainly home-based, the awareness of security needs to be strengthened, and the local level of spiritual and cultural construction has also failed to meet the needs of the elderly. In addition, due to the low level of economic and social awareness, a considerable number of elderly people can not afford to seek medical treatment, or worse, many elderly people do not visit a doctor even if they are sick. Analysis: The survey results showed that some people's misconceptions about old-age care, the low level of support for old-age care services, the lack of specialized certification for some old-age care workers and the inadequate diversification of old-age care service systems. Proposal: We should establish a correct concept of pension service, pay attention to the spiritual needs of the elderly on the basis of ensuring the basic needs of the elderly, and implement a strategy of healthy aging so as to improve and gradually solve the problem of population aging in our country.
\end{abstract}

\section{西安市养老服务体系的现状及调研分析}

\author{
刘利兵", 白宏, 吴梦迪, 谢旭婧, 范青玉, 程就, 孟瑞, 孟姣 \\ 西安培华学院医学院, 西安, 陕西, 中国 \\ *通讯作者
}

关键词: 人口老龄化, 养老服务体系, 西安市

摘要：目的：本文旨在调研西安市养老服务体系现状，分析存在的问题，并提出相应的对策。 方法: 以西安市老年人和养老服务机构为研究对象, 对其养老服务现状进行调研。结果: 调查 显示西安市约 $63 \%$ 的老人均以居家养老为主, 安全防范意识尚需加强, 且当地的精神文化建设 水平也未能满足老年人的需求, 此外由于经济和认识水平的原因相当多的老人在撑不住时才去 就医, 甚至有病也不去就医。分析：部分人的养老理念存在误区, 养老服务保障水平偏低, 且 部分养老服务人员缺乏专业化认证，服务体系不够多样化。建议：树立正确的养老服务理念， 在保障基本养老生活需求的基础上关注老人的精神需求，实施健康老龄化战略，从而改善并逐 步解决好我国人口老龄化问题。

\section{1. 前言}

自上世纪末开始我国已经进入到老龄化社会, 即人口学上所称的“老年型” 社会。近年来, 面对老年人口数量多、老龄化发展速度快的特殊国情, 我国养老服务体系的建设已逐渐取得了 初步的进展, 然而面对养老服务需求的个性化、多样化、广泛化, 老年服务的缺失仍是现阶段 我国面临的重大问题之一，因此，加强养老护理及管理队伍的建设，建立完善的养老服务体系 
是一个亟待解决的问题。本文从中国普遍存在的老龄化现象出发,将西安市部分老年人群体作 为研究对象, 通过调研西安市老年人在养老服务体系中的需求现状,深入分析该地区养老服务 体系中所存在的问题并结合实际情况提出相应的建议,这一研究不仅有利于我国社会保障学体 系的完善,且对促进社会和睦及稳定发展都有积极的现实意义。

\section{2. 国内外典型养老服务业现状及趋势}

近年来，随着居民生活条件和医疗等福利设施的不断完善，全球老龄化进程不断加快，养 老需求的范围不断扩大, 人口老龄化已成为当今全球面临的共同问题[1-3], 养老问题已逐渐成 为社会保障的焦点，因此，加强养老护理及管理队伍的建设，建立完善的养老服务体系是一个 函待解决的问题[4]。许多国家均为加强养老服务专业化的建设采取了一系列的措施。法国的 养老服务业以居家养老为主，养老保险制度实行现收现付制[5]。在促进养老服务发展中主要 采取以下措施: 利用优惠政策引导市场发展; 加强养老服务发展规划和人员培训; 加强监督和 规范养老服务市场; 发挥企业在养老服务市场中的作用[6]。日本的社区养老主要是在政府支 持和资助下，充分利用各级各类资源如人才、技术和社会组织等，向老年人提供医疗、保健、 家政等诸多方面的养老服务，其养老服务模式主要以家庭或亲属照顾为主体、辅之以公共福利 服务和社会化服务的养老服务[7]。美国老年人的养老问题主要由政府和社会承担，于 1981 年 就推行了家庭医疗补助和社区服务计划, 主要通过完善法律法规; 鼓励社会力量兴办养老机构; 实施老年保健计划; 对老年群体制定普遍适用的优惠政策；设立专门的老年人福利养老院、老 人日间托护中心等政策措施保障养老服务业的发展 [8]。英国的家庭养老服务主要策略是由国 家提供家庭护理和医疗服务而建立的一种国民保荐制度，由地方和社区医疗卫生主管机构负 责资金及主要管理体系，本地政府提供家庭帮助和膳食服务。随后,其卫生主管部口和各地地 方政府开始职能分离，社区养老服务体系逐渐减少了主管部口直接提供的服务,增加了商业与 非营利性机构购买服务的渠道,同时也提高了相关的养老费用[9]。澳大利亚建立了由雇主和雇 员分别缴费的养老保障体系，实行老年照顾项目，以家庭为中心强化服务，此外政府以购买服 务的方式向服务机构进行拨款，而服务机构则要通过竞标获得拨款并受政府监督[10]。

虽然通过完善政府监督体系，促进国外养老服务法律化、多样化、专业化，进而在一定程 度上有效地提高了养老服务质量, 然而其在实施与发展过程中仍暴露出一些不足: 如政府财源 的不足，私营养老机构的良莠不齐，执行标准可操作性欠佳，“福利病” 导致的政府服务效率 低下等。

据调查，我国人口老龄化水平已超过国际公认的标志线水平,人口老龄化形势极其严峻, 为此，我国政府也出台了各项政策来支持养老服务业的发展，我国从 2000 年以后，开展体系 化建设。2006 年 2 月，第二次全国老龄工作会议强调要发展 “以居家养老为基础，社区服务 为依托，机构养老为补充” 的中国特色养老服务体系建设。2008 年底, 民政部长李学举在全 国民政工作会议上提出，要建立完善 “以居家为基础、社区为依托、机构为补充” 的养老服务 体系构想。目前国内典型的养老服务业模式主要包括家庭养老服务体系和社会养老服务体系。 家庭养老服务体系是与中国传统文化相适应的延续数千年的养老服务支持系统，服务提供者主 要是老年人本人、配偶、子女以及亲朋好友，其最大的优势是能够提供给老人家庭的温暖和亲 情的关怀。然而在房价、儿女抚养费用不断上涨以及就业竞争等社会经济压力下家庭养老功能 正在逐渐弱化，“养儿防老” 的传统养老模式正受到冲击，仅仅依靠家庭养老服务系统已难以 满足老年人的养老需求。社会养老服务体系是指政府、社会对养老服务有支持意义的各种制度、 政策、机构等方面所构成的系统。该系统是在家庭养老服务功能日趋弱化的背景下产生并发展 形成的。我国的社会养老服务体系主要由居家养老、社区养老和机构养老等三个有机部分组成。 居家养老服务涵盖生活照料、家政服务、康复护理、医疗保健、精神慰藉等，以上门服务为主 要形式。社区养老服务是居家养老服务的重要支撑，具有社区日间照料和居家养老支持两类功 
能，主要面向家庭日间暂时无人或者无力照护的社区老年人提供服务。机构养老服务以设施建 设为重点, 通过设施建设, 实现其基本养老服务功能。

上述国内外养老服务理念和模式均为本课题的开展提供了必要的理论前提和丰富的资料。 本研究以西安市老年人为研究对象,对其养老服务现状进行调研。立足当地,结合实际状况进行 深入研究, 从老人的个人状况及家庭现状为切入点, 采用理论分析与实证检验相结合的研究方法, 对西安市养老服务体系现状、存在问题进行归纳、总结, 以调研结果为依据进行数据分析。

\section{3. 生活现状及需求分析}

\section{1 调查对象生活现状分析}

本文调查结果显示, 西安市老龄化年龄集中在 60 岁以上, 多数老年人收入较低, 健康状 况一般, 且超过一半的老年人只接受过初等教育, 约 $90 \%$ 的老人皆以与其他人共同居住为主要 的生活居住方式，只有少部分人独居。约 $65 \%$ 的老年人不能定时用餐，38\%的老人只能勉强维 持基本的生活自理能力, 且绝大多数老人对目前的居住环境表示不太满意。多数老人只能以散 步或晨练的方式作为主要的日常活动方式。而大部分老人的子女皆因工作繁忙而不能给与老人 生活上的照料和精神上的慰藉。

\section{2 养老方式及安全需求现状}

表 1 的调查结果显示西安市约 $63 \%$ 的老人均以居家养老为主要的养老方式, 超过一半的老 人皆遇到过类似火灾、盗窃、抢劫等的突发状况和电信诈骗、产品诈骗以及盗窃等一系列的安 全事故 $(53 \%)$, 面对上述突发状况和安全事件, 大部分老人因缺乏防骗知识或较低的警惕性 而不能采取紧急防御和救援措施。因此绝大多数老年人希望学习有关预防盗窃, 诈骗等安全预 防常识来加强自身的防范意识。

表 1 养老方式

\begin{tabular}{lcc}
\hline & 类别 & 百分比 $(\%)$ \\
\hline & 居家养老 & 63 \\
养老方式 & 社区养老 & 6 \\
& 机构养老 & 4 \\
\hline
\end{tabular}

\section{3 老年人精神文化现状及需求}

表 2 精神文化现状及需求

\begin{tabular}{ccc}
\hline \multicolumn{1}{c|}{ 文化生活类型 } & 传统型 & $82 \%$ \\
& 时尚型 & $18 \%$ \\
\hline 是否对目前的文化生活满意 & 满意 & $46 \%$ \\
& 一般 & $54 \%$ \\
社区是否经常举办活动 & 是 & $17 \%$ \\
& 否 & $83 \%$ \\
文化生活受到影响的原因 (多选) & 自身身体状况 & $70 \%$ \\
& 经济收入 & $60 \%$ \\
& 没时间参加 & $8 \%$ \\
& 社区设施不到位 & $86 \%$ \\
\hline
\end{tabular}

表 2 调查报告显示，目前西安市老年人大部分仍以电视、广播等相对传统的新闻媒体为主 要的精神文化消费方式，几乎所有老人都希望社区能广泛开展内容丰富、形式多样的活动来丰 富其精神世界。然而由于经济收入的缺乏和硬件实施的不足，目前当地的精神文化建设水平仍 处理基础阶段，导致无法满足老年人的精神文化需求。 


\section{4 老年人健康状况及医疗卫生服务现状}

表 3 调查结果显示, 西安市大部分老年人的身体状况处于正常水平, 但是仍有部分老人被 疾病缠身, 然而由于医疗设施物资的匮乏和部分老年人医保的限制导致接近一半的老年人对待 健康的态度只能是身体处于撑不住的状况才去医院就诊, 有 $13 \%$ 的老人甚至明知有病, 也坚持 不去医院。

表 3 健康状况 及医疗卫生服务现状

\begin{tabular}{ccc}
\hline & 类别 & $82 \%$ \\
& & $18 \%$ \\
\hline \multirow{2}{*}{ 对待健康的态度 } & 及时治疗 & $54 \%$ \\
& 撑不住会去医院 & $33 \%$ \\
& 有病也不去 & $13 \%$ \\
医疗机构存在的问题 (多选) & 床位不够 & $50 \%$ \\
& 收费太高 & $50 \%$ \\
& 服务太差 & $40 \%$ \\
& 离家远，不方便 & $47 \%$ \\
医疗保健情况 & & \\
& 医保 & $82 \%$ \\
& 非医保 & $18 \%$ \\
\hline
\end{tabular}

\section{4. 西安市养老服务体系现状分析}

2016 年 3 月，全国人民代表大会第四次会议审议通过的 “十三五” 规划纲要草案中已明 确提出：要健全养老服务体系，建立以居家为基础、社区为依托、机构为补充的多层次养老服 务体系。实施养老护理人员培训计划, 加强专业化养老服务护理人员和管理人才队伍建设, 为 今后一段时间我市养老服务业的发展提供了有力的政策支持[11]。第六次人口普查数据显示， 西安市 60 岁及其以上人口数量增长率为 $27 \%$, 老年人口增长幅度远超过人口总数增长幅度。 且在未来 30 年来内, 老年人口增长速度仍会继续加快, 该市将由轻度老龄化进入重度老龄化 [12]。据民政部门资料显示，2016 年底，全市共发展养老机构 130 家，其中公办 33 家、民办 97 家，累计建成社区居家养老服务站 649 个、农村幸福院 638 个，各类养老床位共计 4.36 万 张。以居家养老为基础、社区照料为依托、机构养老为支撑的社会养老服务体系已基本建立。 老龄事业蓬勃发展, 高龄保健补贴发放实现了全覆盖, 截止 2016 年底全市享受高龄保健补贴 人数为 173 万人, 年均发放约 4.1 亿元。建成社区服务中心 43 个, 社区服务站 136 个, 室外 活动广场 57 个，省级标准化示范社区 16 个,完成 93 个老旧社区办公用房改造工作。

\section{5. 西安市养老服务体系存在的问题及原因分析}

(1) 养老服务发展理念存在误区

市民仍把养老服务看作是家庭责任，国家主导作用和主体责任未凸显，且对老年人权利保 障不够, 更谈不上满足养老个性化发展需求。

（2）养老服务保障水平偏低

目前养老服务保障水平总体上滞后于经济社会发展水平, 无法满足老年人日益增长的养老 服务需求，保障面有待扩大，服务项目也有限，保障能力更显不足。

（3）养老服务人员缺乏专业化认证

从量上来讲,近年来我市养老护理人员需求量不断增加, 然而目前养老服务人员队伍仍处 于流动性大、人员不稳定的状态。工作薪酬低、工作稳定性不足、工作社会地位低、没有发展 空间、工作没保障等诸多原因都导致广大服务工作者不愿意从事养老服务行业。从质上说，我 
市养老服务人员专业化水平普遍较低，目前我市养老服务行业人员大多来源于人才市场，或经 内部人员介绍而来, 缺乏统一认证标准和人员培养, 大部分工作人员缺乏专业护理相关服务理 念和知识背景。

（4）服务体系不健全

首先, 由于缺乏规范的行业管理机制, 目前我市养老服务规范性程度仍然不够。养老服务 市场处于一种较为盲目、无序的发展状态，造成养老服务体系建设滞后于经济社会发展水平。 近年来，虐老、侵权等事件的层出不穷也给老年福利事业带来诸多负面影响。其次，由于居家 养老服务项目单一，标准及功能不够明确，而社区作为依托力量，缺乏足够的资金、人力和物 质支持，导致居家和社区养老机构提供的相关服务已逐渐无法满足老年人的服务需求。

\section{6. 完善养老服务体系的政策建议}

针对上述养老服务体系中存在的问题, 我们提出了一系列建议:

首先要端正养老服务理念, 加强與论宣传, 使广大市民了解社会化养老的优势, 自觉主动 的参与到社会化养老的活动中。

其次应该从老年人的实际需求出发,在保障基本饮食需求的基础上，扩大老年人的精神世 界, 帮助老年人适应新型互联网生活方式, 建立自信心, 增加其社会存在感, 政府、社区和各 养老机构应提供一定的学习班, 组织老年人学习基本的日常生活常识、防骗常识以及安全逃生 常识, 从而增加其自我支持系统。

此外应将实施健康老龄化战略纳入国民经济和社会发展中的长期规划, 提高对老龄化问题 的认识, 明确国家老龄工作的方向，根据国家的要求，结合实际情况将本地区老龄工作纳入当 地的经济和社会发展计划中，采取分工负责和齐抓共管方式，对老龄工作有管理、有服务、有 措施、有检查。将家庭养老和社会养老相结合，建立以家庭养老为基础，社区养老服务网络为 辅助, 公共福利设施养老手段为补充, 社会保险制度为保障的居家养老体系, 把老年人自身、 家庭、社会和国家作用有机的组合起来，使之发挥出最佳效用。且近年来随着高科技的不断发 展, 通过互联网+医护养的一体化人才培养基地构建也逐步为社会培养医疗及护理人员提供了 丰富的思路和有力的现代化训练平台[13], 我们应抓住新的机遇, 迎接挑战, 培养出更多的高 水平养老护理服务人才,力争实现 “老有所养、老有所医、老有所为、老有所学、老有所教、 老有所乐”, 从而改善并逐步解决好我国人口老龄化问题。

\section{项目资助}

西安市社科规划项目培华专项 16PH05。

\section{参考文献}

[1] 王晶晶，葛高琪，郭翼天,等. 国内外社区居家养老模式现况 [J]. 中国老年学, 2017, 37(5):1277-1279.

[2] 曹楠, 刘启贵. 近十年国内外有关老年护理研究文献的可视化分析[J]. 中国护理管理, 2017, 17(4):537-542.

[3] 刘巧红, 龙玉其. 简论当前全球养老保险制度发展的时代特征[J]. 桂海论丛, 2014(2):87-90.

[4] 张海川, 张利梅. 个性化养老服务需求的调查分析一一以成都市为例 [J]. 首都经济贸易大 学学报, 2017, 19(1):58-65.

[5] 史建平. 养老金制度与体系[M]. 中国发展出版社, 2007.

[6] 刘婉娜，胡成. 法国居家养老服务业的发展及启示[J]. 宏观经济管理, 2012(7):81-82. 
[7] 汪国华，张登国. 健全养老社会服务体系与机制一一基于中外比较视角 [J]. 现代经济探讨, 2014(9):83-87.

[8] 张淑谦, 傅建敏, 张铁山. 国内外养老服务业发展研究综述 [J]. 新西部: 理论版, 2014(17):171-171.

[9] 葛江霞. 英国养老服务体系的三个借鉴 $[\mathrm{J}]$. 社会与公益, 2015(4):88-89.

[10] 廖成丽. 论我国城乡统筹的养老服务体系的构建[D]. 南昌大学, 2010 .

[11] 丛春霞，彭歆茹. 城市居民居家养老服务供需问题研究 [J]. 东北财经大学学报, 2017(1):49-56.

[12] 刘奕，王炳．西安市社区居家养老服务研究[J]．西部学刊, 2017(2):65-68.

[13] Libing L, Xin X, Yihong H, et al. Internet + Talent Training Base Construction for Integration of Medical Treatment, Nursing and Elderly Care[C]// Joint International Information Technology, Mechanical and Electronic Engineering Conference. 2016. 